\title{
Atendimento Educacional Especializado: uma nova proposta de educação inclusiva
}

\author{
Cláudia Valente Cavalcante*
}

\section{Resumo}

O Atendimento Educacional Especializado (AEE) é uma política nacional de educação especial na perspectiva da educação inclusiva, publicada pelo Ministério da Educação (MEC) em 2008, e inaugura um novo marco legal, teórico e organizacional da educação pública brasileira. $\mathrm{O}$ AEE tem como objetivos possibilitar a articulação entre atendimento escolar e especializado em unidades escolares, facilitar acesso e atendimento ao aluno deficiente e sua família e possibilitar o desenvolvimento da aprendizagem e da convivência sem discriminação. Esse atendimento é ofertado no contraturno em Salas de Recursos Multifuncionais (SRM), que são ambientes dotados de equipamentos, mobiliários e materiais didáticos e pedagógicos para acessibilidade e são organizados e destinados à implantaçáo de espaços de AEE. Este artigo apresenta o resultado de orientação de oito Trabalhos de Conclusão de Curso (TCC) de especialização a distância em Atendimento Educacional Especializado (AEE), ministrado pela Universidade Federal do Ceará entre 2010 e 2011, cujo objetivo foi qualificar professores para AEE da rede pública de ensino para atuarem em suas unidades escolares. Cada cursista elaborou um TCC baseado em estudo de caso de um aluno deficiente matriculado na rede pública de ensino de Goiânia. A partir de pesquisas bibliográficas, observaçóes do aluno no ambiente escolar e familiar, entrevistas com professores regentes, pais e equipe multidisciplinar, foi elaborado um plano individual de AEE que prevê estratégias de inclusão para o desenvolvimento da aprendizagem, conforme as necessidades e possibilidades concretas dos alunos e da escola.

Palavras-chave: atendimento educacional especializado, educação inclusiva, alunos com deficiência, estudo de caso.

Specialized Educational Services: a new proposal for inclusive education

\begin{abstract}
Specialized Educational Services (AEE) is a national policy on special education from the perspective of inclusive education, announced by the Ministry of Education in 2008, a new legal, theoretical and organizational milestone in Brazilian public education.

* Doutoranda pelo Programa de Pós-graduação em Educação (PPGE) da Pontifícia Universidade Católica de Goiás (PUC-GO). Bolsista Capes/Prosup. E-mail: cavalcante70@yahoo.com.br.
\end{abstract}


AEE aims to facilitate dialogue between educational and specialized services in schools, facilitate access and care for disabled students and their families and also provide learning and integration without discrimination. This service is provided during extra-curricular activity time, in Multifunction Resource Rooms, equipped and furnished for accessibility, provided with didactic and pedagogical materials and organized and intended for the implantation of the AEE. This article presents the results of eight end-of-course papers of distance postgraduate courses in Specialized Educational Services, run by the Federal University of Ceará from 2010 to 2011, to qualify school teachers for AEE in public schools. Each course member wrote an end-of-course paper based on the case study of a disabled public school student in Goiânia. After bibliographical research, observation of students in the school and home environments, interviews with classroom teachers, parents and a multidisciplinary team, an individual AEE plan was drawn up which proposed inclusive strategies to encourage learning in accordance with the concrete needs and possibilities of the students and the school.

Keywords: specialized educational services, inclusive education, disabled students, case study.

Michel Foucault (2010), filósofo francês, em sua obra História da loucura, que completa 50 anos este ano, ajuda-nos a pensar como se deu o isolamento dos "diferentes" em diversas etapas da história. O modo pelo qual pensamos o sujeito está diretamente ligado as suas distintas concepçóes construídas historicamente. Assim,

seria interessante tentar ver como se dá, através da história, a constituição de um sujeito que não é dado definitivamente, que não é aquilo a partir do que a verdade se dá na história, mas de um sujeito que se constitui no interior mesmo da história, e que é a cada instante fundado e refundado pela história. (FOUCAULT, 1999, p. 10)

Nessa obra, Foucault desvela os mecanismos de isolamento e confinamento daqueles que eram considerados "inapropriados" para viver em sociedade. Nesse sentido, temos que, ao final da Idade Média, com o desaparecimento da lepra, os leprosários esvaziam-se, tornando-se espaços de confinamento de sujeitos "desprovidos de razão", sejam eles loucos, pobres, presidiários, ou qualquer outro que fugisse ao padrão de normalidade. Nesse grupo, penso que, provavelmente, os deficientes estariam incluídos.

Sem a pretensão de debruçar-se sobre a obra de Foucault, mas de apropriar-se de alguns de seus conceitos para introduzir a temática dicotômica inclusão e exclusão de deficientes no sistema escolar, este artigo pretende discutir a perspectiva do Atendimento Educacional Especializado 
(AEE) e fazer um relato de oito Trabalhos de Conclusão de Curso (TCC) de Formação Continuada a Distância de Professores em AEE da Universidade Federal do Ceará (UFC).

\section{Política nacional de educaçáo especial na perspectiva da educaçáo inclusiva}

Em virtude de séculos de exclusão dos "desprovidos de razão", como descreve Foucault, os deficientes, de modo geral, assim como seus pais e familiares, enfrentaram/enfrentam dificuldades para se inserirem em uma sociedade em que seus princípios são orientados por um pensamento racionalista sobre a normalidade. Daí que nesta sociedade os lugares são ocupados, preferencialmente, pelos denominados "normais" e tudo para esses converge, como, por exemplo, educação, emprego, dentre outros.

Frente a essa problemática, diversos movimentos mundiais em favor do reconhecimento legítimo de participação desses sujeitos nos distintos espaços de socialização, o tema inscreve-se como imprescindível nas discussóes nas agendas políticas nacional e internacional.

A Constituição Brasileira (CF) de 1988 assegurou o direito de todas as pessoas com deficiência à educação. Em seguida, com avanços da legislação, emerge uma nova interpretação da Educação Especial. Somou-se a esse direito, o direito ao Atendimento Educacional Especializado que complementa e não substitui o ensino escolar comum, e, sim, ratifica o acesso e frequência de alunos com deficiência a escolas regulares. Ao assegurar tais direitos, a CF não exclui nenhum aluno em razão de sua classe social, raça, gênero, idade, cor ou deficiência, e assim está em seu texto:

a igualdade de condiçóes de acesso e permanência na escola (art. 206, I, $\mathrm{CF}$ ), acrescentado que o dever do Estado com a educação será efetivado mediante a garantia de acesso aos níveis mais elevados do ensino, da pesquisa e da criação artística, segundo a capacidade de cada um (art. 208, V, CF ). (BRASIL, 1988)

A igualdade de acesso e permanência na escola teve/tem distintas interpretaçóes ao longo de sua história, o que gerou formas diferenciadas de atendimento. Segundo Fávero, Pantoja e Mantoan (2007), o Atendimento Educacional Especializado, chamado pela Lei de Diretrizes e Bases 
da Educação Nacional (BRASIL, 1996) de Educação Especial, apresenta duas facetas.

A primeira concepção organizou escolas separadas, chamadas de especiais ou especializadas, voltadas apenas para pessoas com deficiência, nas quais normalmente se pode cursar a Educação Infantil e o Ensino Fundamental - em outras palavras, substituem absolutamente o acesso a uma escola comum. Nessa linha, seus defensores não negam direitos, pois o aluno pode ter acesso a algum tipo de ensino, e isso seria suficiente.

A segunda trata-se da Educação Especial defendida pelos movimentos que apoiam a inclusão escolar, isto é, a frequência a um mesmo ambiente por alunos com ou sem deficiência. O AEE, nessa perspectiva, é apoio, complemento, destinado a oferecer "aquilo que é de específico na formação de um aluno com deficiência, sem impedi-lo de frequentar, quando na idade própria, ambientes comuns de ensino, em estabelecimentos oficiais comuns" (FÁVERO; PANTOJA; MANTOAN, 2007, p. 17). Nessa vertente, a negaçáo de diretos ocorre quando tal atendimento acaba substituindo totalmente os serviços oficiais comuns:

[Fica] caracterizada a negação ou restrição (discriminaçáo), pois é direito de toda criança, mesmo que apresente características muito diferentes da maioria, conviver com sua geraçáo, sendo que o espaço privilegiado para que isso ocorra é a escola. (FÁVERO; PANTOJA; MANTOAN, 2007, p. 17)

Tal discriminação estaria contrariando o Artigo I da Convenção relativa à Luta contra a Discriminação no Campo do Ensino, de 15/12/60, ratificada pelo Brasil em 19/04/1968 e promulgada pelo Decreto n. 63.233, de 06/09/1968.

Outro marco importante na luta pela inclusão é a Declaração de Salamanca (1994), que ratifica à criança o direito fundamental à educação. Também, deve ser dada a oportunidade de atingir e manter o nível adequado de aprendizagem, assegurando, dentre essas crianças, àquelas com necessidades educacionais especiais o acesso a uma escola regular que seja capaz de satisfazer tais necessidades por meio de metodologias diferenciadas.

Posterior à Lei de Diretrizes e Bases da Educação Nacional (LDBEN/1996), que assegura o atendimento a todos e o direito à educação, surge o documento da Convenção da Guatemala (1999), em que o Brasil é signatário dessa convenção, e foi aprovado em Congresso Nacional por 
meio do Decreto n. 3.956/2001. Nesse documento, afirma-se que pessoas com deficiência têm os mesmos direitos humanos e liberdades fundamentais que os demais.

Essa convenção tem valor de norma constitucional, visto que se refere a diretos e garantias fundamentais da pessoa humana. $\mathrm{O}$ documento esclarece a impossibilidade de diferenciação com base na deficiência, definindo a discriminação como:

[...] toda diferenciação, exclusão ou restrição baseada em deficiência, antecedente de deficiência, conseqüência de deficiência anterior ou percepção de deficiência presente ou passada, que tenha o efeito ou propósito de impedir ou anular o reconhecimento, gozo ou exercício por parte das pessoas portadoras de deficiência de seus diretos humanos e suas liberdades fundamentais. (CONVENÇÃO da GUATEMALA, 1999, art I, n. 2, a)

Segundo esse documento, admitem-se diferenciações com base na deficiência para permitir o acesso aos direitos, e não para fins de negar o exercício deles. Um aluno com graves problemas motores, por exemplo, pode necessitar de um computador em aula, então isso deve ser garantido a ele. Trata-se de uma diferenciação em razão de sua deficiência e para permitir a ele continuar no processo de aprendizagem, assim como seus colegas. Contudo, segundo a Convenção, e conforme Mantoan (2010, p. 18), "não será discriminação só se esse aluno não for obrigado a aceitar tal diferenciação".

Nos termos das convençôes internacionais e da CF, o Atendimento Especializado Educacional, também chamado de Educação Especial, é uma forma de tratamento diferenciado, desde que: seja adotado quando realmente existir uma necessidade educacional especial, ou seja, algo do qual os alunos sem deficiência não precisam; seja oferecido preferencialmente no mesmo ambiente (escola comum) frequentado pelos demais alunos; e se houver necessidade de ser oferecido à parte, que isso ocorra sem dificultar ou impedir que crianças e adolescentes com deficiência tenham acesso às salas de aula do ensino comum no mesmo horário em que os demais alunos a frequentam; e, por fim, não seja adotado de forma obrigatória, ou como condição para o acesso do aluno com deficiência ao ensino comum.

Analisada a partir dessa perspectiva, pode-se dizer que a Educação Especial é uma forma de tratamento diferenciado que leva à inclusão e não à exclusão de direitos (FÁVERO; PANTOJA; MANTOAN, 2007). 
No Decreto n. 6.571/2008, em convergência aos princípios da Convenção Internacional sobre os Direitos das Pessoas com Deficiência, conhecida como Declaração da Organização das Naçóes Unidas (ONU), a educação inclusiva passa a ser definida como uma modalidade de ensino que perpassa todos os níveis e etapas da educação, cujo objetivo é garantir a todos iguais condiçóes de acesso, permanência e êxito no processo de escolarizaçáo nas salas de aulas comuns das escolas regulares. Nessa compreensão, a Educação Especial suplementa e complementa a educação e se realiza por meio de oferta do AEE a alunos com deficiência visual, intelectual, física, surdez, cegueira, baixa visão, surdo-cegueira, Transtornos Globais de Desenvolvimento (TGD) e altas habilidades/superdotação.

\section{Atendimento Educacional Especializado: uma nova perspectiva e inclusáo escolar}

Com a política nacional de educação especial na perspectiva da educação inclusiva, publicada pelo Ministério da Educação (MEC) em 2008, inicia-se um novo marco legal, teórico e organizacional da educação brasileira. Com base na implementação do Atendimento Educacional Especializado, é uma modalidade de acompanhamento complementar ou suplementar à formação de alunos com deficiência, sendo ela não substitutiva à educação escolar regular. O AEE é uma nova interpretação da Educação Especial, conforme Mantoan (2010), e tem suas próprias especificidades legais e organizacionais.

Ofertado em todos os níveis, etapas e modalidades do ensino em escolas regulares, prioritariamente, o AEE pretende possibilitar a articulação entre atendimento escolar e especializado em unidades escolares, facilitar acesso e atendimento ao aluno deficiente e sua família, bem como possibilitar o exercício da convivência sem discriminação e de aprendizagem. $\mathrm{O}$ atendimento especializado é obrigatório aos sistemas de ensino, mas a matrícula do aluno deficiente é opcional.

Conforme o Decreto n. 6.517/2008, art. 1º, parágrafos I e II,

I - Considera-se atendimento educacional especializado o conjunto de atividades, recursos de acessibilidade e pedagógicos organizados institucionalmente, prestado de forma complementar ou suplementar à formação dos alunos no ensino regular. 
II - O atendimento educacional especializado deve integrar a proposta pedagógica da escola, envolver a participação da família e ser realizado em articulaçáo com as demais políticas públicas.

Para a realização do AEE, segundo o art. $3^{\circ}$, o Ministério da Educação prestará apoio técnico e financeiro às açóes para a oferta desse atendimento.

I - implantação de salas de recursos multifuncionais;

II - formaçáo continuada de professores para o atendimento educacional especializado;

III - formação de gestores, educadores e demais profissionais da escola para a educação inclusiva;

IV - adequação arquitetônica de prédios escolares para acessibilidade;

$\mathrm{V}$ - elaboração, produção e distribuição de recursos educacionais para a acessibilidade; e

VI - estruturação de núcleos de acessibilidade nas instituições federais de educação superior.

As Salas de Recursos Multifuncionais (SRM) são ambientes dotados de equipamentos, mobiliários e materiais didáticos e pedagógicos para a oferta do Atendimento Educacional Especializado e de recursos de acessibilidade organizados e destinados à implantação e organização de espaços de AEE, possibilitando sua oferta no contraturno ao ensino regular nas escolas públicas de educação básica.

O AEE é realizado, prioritariamente, na sala de recursos multifuncionais da própria escola ou em outra escola de ensino regular, no turno inverso da escolarização, não sendo substitutivo às classes comuns, podendo ser realizado, também, em Centros de Atendimento Educacional Especializado da rede pública ou de instituiçôes comunitárias,confessionais ou filantrópicas sem fins lucrativos,conveniadas com a Secretaria de Educação ou órgão equivalente dos Estados, Distrito Federal e Municípios. (BRASIL, 2009, p.2)

Nessas salas são propostas e desenvolvidas atividades que se diferenciam das que ocorrem em sala de aula comum. Essas atividades não são substitutivas, tampouco são repetiçóes de conteúdos programáticos desenvolvidos em sala de aula ou reforço escolar. São um conjunto de procedimentos específicos, mediadores do processo de apropriação e produção de conhecimentos que atenda as especificidades de cada aluno com deficiência (BRASIL, 2009). 
Para que as escolas da rede pública possam receber as SRM, elas devem atender a certos critérios, tais como, ter matrícula de alunos com deficiência, transtornos globais de desenvolvimento e altas habilidades/ superdotação registradas no Censo Escolar/MEC/INEP, disponibilizarem professores com formaçáo inicial ou continuada para o Atendimento Educacional Especializado, ter espaço para a instalaçáo dos equipamentos e recursos. Também, as Secretarias Municipais e Estaduais de Educação devem estar inscritas no Plano de Açóes Articuladas (PAR). Para tanto, é necessário que o gestor do município, do estado ou do Distrito Federal garanta professor para o AEE, bem como o espaço para a sua implantação.

O professor, para atuar na Sala de Recursos Multifuncional, de acordo com o MEC (BRASIL, 2009, p. 17), deverá ter graduação, pós-graduação e/ou formação continuada que o habilite no atendimento. Suas principais atribuiçôes são:

a) Atuar, como docente, nas atividades de complementação ou suplementaçâo curricular; b) Atuar de forma colaborativa com professor da classe comum para a definição de estratégias pedagógicas que favoreçam o acesso do aluno com necessidades educacionais especiais ao currículo e a sua interaçáa no grupo; c) Promover as condiçôes para a inclusão dos alunos com necessidades educacionais especiais em todas as atividades da escola; d) Orientar as famílias para o seu envolvimento e a sua participação no processo educacional; d) Informar a comunidade escolar acerca da legislação e normas educacionais vigentes que asseguram a inclusão educacional; e) Participar do processo de identificaçáo e tomada de decisōes acerca do atendimento às necessidades educacionais especiais dos alunos; $\mathrm{f}$ ) Preparar materiais específicos para o uso dos alunos na sala de recursos; g) Orientar a elaboração de materiais didático-pedagógicos que possam ser utilizados pelos alunos nas classes comuns do ensino regular; h) Indicar e orientar o uso de equipamentos e materiais específicos e de outros recursos existentes na família e na comunidade; i) e Articular, com gestores e professores, para que o projeto pedagógico da instituição de ensino se organize coletivamente numa perspectiva de educação inclusiva.

Desse modo, percebe-se que, para a concretização dessa proposta, é necessária parceria entre professor de classe comum, professor do AEE e família do aluno e comunidade escolar. $\mathrm{O}$ espaço escolar deve ser pensado, planejado e adaptado para sua acessibilidade e o Projeto Político-Pedagógico articulado com tais necessidades. 
Curso de Formação Continuada a Distância de Professores para o AEE: reflexóes mediadas pela orientaçáo de oito Trabalhos de Conclusáo de Curso

O curso de especialização (lato sensu) Formação Continuada de Professores para o Atendimento Educacional Especializado (AEE), da Faculdade de Educação da Universidade Federal do Ceará, foi realizado entre fevereiro de 2010 e outubro de 2011. Os objetivos do curso foram: a) qualificar mais de 3.369 professores (graduados em Pedagogia e/ou licenciatura) da rede pública de 103 municípios-polo e 521 municípios de abrangência do programa educação inclusiva: direito à diversidade do Ministério da Educação (MEC); b) proporcionar condições de conhecer e colocar em prática o Atendimento Educacional Especializado, um novo serviço da Educação Especial, prescrito pela política nacional de educação especial, na perspectiva da educação inclusiva (BRASIL, 2009).

Foi proposta como TCC a elaboração de um Plano de Atendimento Educacional Especializado a partir de um estudo de caso. Segundo Verde, Poulin e Figueiredo (2010), para realizar esse estudo e elaborar o plano de AEE desse aluno, o professor do AEE segue as seguintes etapas: Etapa 1: Proposição do caso; Etapa 2: Análise e clarificação do problema; Etapa 3: Estudo e identificação do problema; Etapa 4: Solução do problema e Etapa 5: Elaboração do plano de AEE.

A elaboração desse plano pressupóe a descrição dos objetivos do plano, a organização do atendimento, atividades a serem desenvolvidas no atendimento ao aluno, assim como a seleção e adequação de materiais para atender suas necessidades, seleção de materiais e equipamentos a serem adquiridos, tipos de parcerias necessárias para o atendimento e produção de materiais, professores que receberão orientação do professor do AEE, avaliação dos resultados e reestruturação do plano (caso dos objetivos que náo foram atingidos).

A metodologia proposta foi estudar situações-problema, envolvendo alunos oriundos das escolas das redes de ensino em que atuam as cursistas, e indicar um plano que atendesse às necessidades individuais e coletivas do aluno deficiente. O curso fundamentou-se no Problem Based Learning (PBL), que é uma aprendizagem mediada por problemas.

Durante o período de junho a outubro de 2011, foram orientados oito TCCs realizados por professoras efetivas da rede municipal de ensino 
de Goiânia: sete graduadas em Pedagogia e uma em Letras/Inglês e Fonoaudiologia. Acerca dos temas discutidos, Leite (2011), Santos (2011) e Silva (2011) investigaram crianças com Transtornos Globais do Desenvolvimento (TGD). Dantas (2011), por sua vez, investigou uma criança com Síndrome de Angelman. Andrade (2011) observou um aluno de oito anos de idade que possui surdez profunda bilateral. Carvalho (2011) e Gonçalves (2011) pesquisaram alunos com paralisia cerebral em distintas escolas. E Silva (2011) estudou sobre um aluno com deficiência intelectual.

Os Transtornos Globais de Desenvolvimento englobam alguns transtornos, como o autismo (TA). Segundo pesquisas bibliográficas, baseadas em Lowenthal e Filho, Camargo e Paes e Klin, realizadas por Leite (2011), Silva (2011) e Souza (2011), que estudaram crianças com autismo em distintas unidades escolares, o autismo infantil manifesta-se, principalmente, em condutas com prejuízo na interação social, alterações da comunicação marcadas por uso de formas náo verbais e padróes limitados ou estereotipados de comportamentos e interesses. Há ausência de comportamentos que indiquem compartilhamento de experiência e comunicação. Podem repetir o que lhes é dito (ecolalia imediata) e há uma falta de reciprocidade social ou emocional.

O diagnóstico realizado pelas investigadoras, por meio de observaçôes sistemáticas das crianças autistas no ambiente escolar e entrevistas com familiares, professores, e por uma equipe multidisciplinar, possibilitou perceber dificuldades de socialização e de expressão oral, movimentos repetitivos, dificuldade de concentração nas atividades propostas, inquietação e limitação na comunicação.

Outro aspecto observado é a inflexibilidade, cujas reações são: prejuízo quanto à antecipação, controle rigoroso do ambiente ou da rotina, rígido perfeccionismo, o que prejudica a reciprocidade social, pois as relaçóes sociais exigem antecipar, dar sentido, significados e ter propósitos. Tarefas essas que são consideradas difíceis para esses alunos, fator negativo para sua permanência na escola, pois alteram sua rotina, que eles tanto valorizam.

Nesses casos de TGD, os planos de AEE, elaborados pelas investigadoras Leite (2011), Santos (2011) e Silva (2011), propóem atividades escolares para o desenvolvimento de competências sociocognitivas que envolvam rotinas da escola, com vivências imediatas e futuras de caráter colaborativo, por meio de atividades pedagógicas, lúdicas, recreativas e de reciprocidade social, assim como orientações para as famílias dos autistas. 
No ambiente escolar, os planos de AEE orientam os professores de sala e colegas a: incentivar a participação em atividades coletivas; oferecer atendimento escolar integral; oferecer atividades diversas, auxiliando no rompimento da repetiçáo e estereotipia; utilizar TA, entre outras. Quanto ao ambiente familiar e parcerias, os planos preveem orientação à família e contato semanal para discutir possíveis avanços ou retrocessos e, por fim, estabelecer parcerias com uma equipe multidisciplinar.

Dantas (2011) investigou uma criança de nove anos de idade, educanda do Ciclo I agrupamento C, em uma escola municipal de Goiânia, que tem microcefalia e diagnóstico de Angelman. Em seus estudos bibliográficos, de acordo com o Dr. Paulo Plaggerp, do Hospital de Clínicas de São Paulo, essa síndrome é uma doença genética e "não há tratamento disponível para os portadores dessa síndrome. É possível apenas dar tratamento de suporte ou psicossomático, procurando amenizar os sintomas e melhorar a qualidade de vida dessas pessoas" (apud DANTAS, 2011, p. 26).

$\mathrm{O}$ estudo de caso revelou que a criança com Angelman é dependente parcialmente para locomoção, falta equilíbrio e apresenta movimentos involuntários. Não reconhece as letras, mas gosta de livros ilustrados. Quanto à linguagem, apresenta limitação e comunica-se por apontamentos e expressões da face. A mãe já trabalha com a filha por meio de comunicação alternativa, faz uso de pranchas e outros recursos para auxiliá-la em casa.

Diante da situação, Dantas (2011) elaborou um plano de AEE com várias açóes, dentre elas: o auxílio de um cuidador; a matrícula da criança em uma turma de educandos da mesma idade; orientação à família sobre a importância da frequência regular para favorecer o desenvolvimento da educanda; reserva e garantia de um período semanal para o planejamento, organização do trabalho e confecção de materiais para auxiliar o professor de sala; proposição de atividades de socialização; e oportunizar quinzenalmente um momento dos professores do AEE na sala de ensino regular, para observá-la in loco.

O quinto TCC, realizado por Andrade (2011), trata de uma criança de oito anos de idade com surdez profunda bilateral. Em suas observaçóes, percebeu-se que o aluno ainda não estava alfabetizado em Língua Brasileira de Sinais (Libras) e em Língua Portuguesa, porém já conhecia algumas cores em Libras e, em casa, utiliza os sinais domésticos (símbolos esotéricos), pois a família desconhece o uso da Libras. A mãe do aluno está iniciando o curso no Centro Municipal de Apoio à Inclusão (CMAI), no horário em que 
o filho é atendido. A criança apresenta ainda dificuldades na coordenação motora fina, o que dificulta o seu aprendizado tanto em Libras (dificuldade em fazer os sinais com as mãos), quanto em Língua Portuguesa (dificuldade em segurar o lápis na hora da escrita), porém já tem acompanhamento de uma equipe multidisciplinar.

Andrade (2011, p. 14) propóe três momentos didático-pedagógicos em seu plano:

1. AEE em Libras, onde os conhecimentos dos diferentes conteúdos curriculares são explicados nessa língua por um professor, sendo o mesmo preferencialmente surdo; 2. AEE para o ensino de Libras, no qual os alunos com surdez terão aulas de Libras, favorecendo o conhecimento e a aquisição, principalmente de termos científicos, de acordo com o estágio de desenvolvimento da Língua de Sinais em que o aluno se encontra; 3. AEE para o ensino da Língua Portuguesa, no qual são trabalhadas as especificidades desta língua para pessoas com surdez.

Orienta-se que o planejamento do AEE deve ser elaborado e desenvolvido conjuntamente pelos professores que ministram aulas em Libras, professor de classe comum e professor de Língua Portuguesa. $\mathrm{O}$ atendimento ocorre diariamente no contraturno na sala de aula comum. Quanto à família, esta necessita conscientização da importância e necessidade do uso do Aparelho de Amplificaçáo Sonora Individual (AASI) e da utilização da Libras no cotidiano. Sua proposta é proporcionar uma melhor interação entre escola e família, auxiliar no planejamento da professora de sala comum, bem como no papel do professor intérprete em sala. Segundo Andrade (2011, p. 21), "o AEE para esse aluno viabilizaria a aprendizagem em ambiente bilíngue, melhoraria sua participação em sala de aula comum e forneceria ao aluno a compreensão dos conteúdos trabalhados em sala de aula”.

Gonçalves (2011) e Carvalho (2011) investigaram dois alunos (um de cinco e o outro de onze anos de idade, respectivamente) com paralisia cerebral. Ambos os casos apresentam deficiências físicas em comum: possuem comprometimento motor global, são cadeirantes, têm pouco desenvolvimento em relaçáo à linguagem verbal, mas conseguem manifestar suas vontades e necessidades.

Quanto aos aspectos escolares da criança de cinco anos, ela obedece a ordens simples. Tem bom esquema corporal. Reconhece algumas letras. O cognitivo é preservado, há comprometimento motor significativo, tem dificuldade em realizar função bimanual e motricidade fina, sua preensão é 
primitiva. No desenvolvimento dos aspectos cognitivos, está aprendendo os conceitos básicos e noção espacial. Apresenta boa interação com o ambiente, mostrando-se interessado, contudo a escola não possui acessibilidade física, segundo observaçóes de Gonçalves (2011).

Já quanto à criança de onze anos, Carvalho (2011) observou que ela, no ambiente escolar, é acompanhada por uma cuidadora. As atividades direcionadas a ela são diferenciadas e há interesse por reconto de histórias, informática, música e aulas de inglês. Contudo, há dificuldade de permanência na sala de aula por mais tempo, sendo que a cuidadora o leva para dar voltas pela escola constantemente.

Para o atendimento dessas crianças, Gonçalves (2011) e Carvalho (2011) propóem conhecer as propostas das professoras regentes para planejar atividades pedagógicas que contribuam para a inserção desse aluno na rotina da sala de aula, assim como pensar maneiras que rompam as barreiras que os limitam no seu processo de aprendizagem e acessibilidade. As autoras sugerem o uso da Tecnologia Assistiva (TA), utilizando recursos de alta e baixa tecnologia, uso de engrossadores de lápis e caneta para auxiliar na escrita, de alfabetos e números móveis de vários tamanhos; trabalhar e utilizar a Comunicação Aumentativa e Alternativa (CAA), como a prancha de comunicação com símbolos para possibilitar a ampliação do vocabulário desses alunos; adaptação da órtese moldável para o uso do computador e talheres; e treinar o uso do teclado de colmeia e mouse especial para o desenvolvimento de sua escrita por meio de softwares específicos.

No que se refere às parcerias, orientar os profissionais da escola e familiares com os conhecimentos específicos para o atendimento das necessidades dos educandos, referentes à mobilidade, adequação postural, autocuidado, desenvolvimento da linguagem, uso da TA/CAA, para promover a autonomia, bem como estabelecer parcerias com profissionais da saúde e, por fim, orientar o diretor da escola na obtenção de recursos para adequaçóes físicas de acessibilidade desses alunos em todos os espaços da unidade escolar.

Por fim, o último TCC, elaborado por Silva (2011), que pesquisou um aluno de oito anos de idade, que tem deficiência intelectual e frequenta o terceiro ano do Ensino Fundamental em uma escola do município. Em suas pesquisas bibliográficas, Silva (2011) cita Coll, que define deficiência intelectual ou atraso mental como um termo que se usa quando uma pessoa apresenta certas limitaçóes no seu funcionamento mental e no desempenho de tarefas como as de comunicaçáo, cuidado pessoal e de relacionamento 
social. Essas limitações provocam uma maior lentidão na aprendizagem e no desenvolvimento dessas pessoas.

Segundo Silva (2011), o diagnóstico atesta que essa criança investigada tem dificuldade em estabelecer vínculos, falta de atenção e concentração, problemas com coordenação motora fina, faz trocas fonéticas e ainda apresenta incompreensão no que lhe é solicitado.

Conforme suas observaçóes na escola, o aluno compreende as regras e normas da escola, mas não aceita ser contrariado, tornando-se agressivo. Mostra-se muito dependente da professora, exigindo sua atençáo exclusiva e rejeita o auxílio dos colegas. Relaciona-se com alguns colegas e possui professora de apoio.

Com relação à cognição, ele consegue associar e emparelhar figuras do jogo da memória e faz relações simples. No raciocínio lógico, consegue memorizar e relacionar quantidade, no máximo até 10 . Apresenta dificuldades na oralidade, leitura e escrita. Não consegue acompanhar o conteúdo do terceiro ano, pois o aluno gosta de estudar assuntos do seu interesse (carros, comidas, brinquedos, etc.). A escola o encaminhou para avaliação psicológica e acompanhamento com especialista ao Centro Integrado Médico Psicológico (CIMP), pois o aluno apresenta dificuldades de fala. Todavia, mesmo apresentando essa dificuldade, em determinados contextos é possível compreender sua fala.

Silva (2011) realizou um plano de AEE cujos objetivos são: a) propiciar ao aluno o desenvolvimento de suas potencialidades na leitura e escrita e conceitos lógico-matemáticos; b) providenciar novos materiais de baixa tecnologia (como joguinhos da memória, alfabeto móvel, boliche de números, jogos que exigem raciocínio lógico) e atividades diversificadas do mesmo conteúdo; c) promover encontros com a professora da sala de aula para elaboração de atividades pedagógicas que promovam aprendizagem significativa, e d) gerar atividades de socialização entre os alunos.

Por fim, quanto às parcerias, orientar professores e toda comunidade escolar a estabelecer contato e comunicação com a família, o Apae, em que o aluno já recebe atendimento, e com médicos que já o atendem na rede municipal de saúde.

\section{Consideraçóes finais}

Este artigo pretendeu apresentar o resultado de uma orientação de oito Trabalhos de Conclusão de Curso, do curso de especialização em 
Atendimento Educacional Especializado, oferecido pela Universidade Federal do Ceará, modalidade a distância, realizado entre os meses de fevereiro de 2010 e outubro de 2011. A orientação deu-se de junho a outubro de 2011.

Os oito trabalhos foram elaborados por professoras atuantes no sistema de ensino da rede municipal de Goiânia. A proposta do TCC foi elaborar um plano de AEE a partir de um estudo de caso de um aluno matriculado no ensino público. Os procedimentos utilizados para a investigaçáo foram: observação direta do aluno no espaço escolar, entrevistas com a família, professora regente e comunidade escolar; análise documental de diagnósticos e laudos de especialistas da área da saúde e o Projeto Pedagógico da escola. Os temas investigados nas pesquisas foram: autismo, síndrome de Angelman, surdez profunda bilateral, deficiência física e deficiência intelectual. Os casos foram identificados por observaçóes sistemáticas e, a partir disso, foi elaborado um plano de AEE para atender às necessidades específicas do aluno deficiente.

O plano de AEE é um instrumento que deve ser realizado por um profissional qualificado para o atendimento especializado e tem como objetivo auxiliar o professor regente na superaçáo desse aluno quanto aos aspectos sociais, cognitivos, motores e afetivos. $\mathrm{O}$ atendimento é realizado em Salas de Recursos Multifuncionais no contraturno da escola.

Percebeu-se nos trabalhos de investigação que cada plano de AEE foi pensado, elaborado e sistematizado a partir de um sujeito real com suas especificidades, necessidades e limitaçóes, levando em consideração as condições da escola, bem como dos profissionais que nela atuam. Ademais, é um plano personalizado que compreende o sujeito em sua totalidade e potencialidade.

Outro aspecto importante dessa proposta é o grande avanço na política de educação inclusiva como uma rede colaborativa entre o Ministério da Educação, que promove a capacitação profissional do professor de AEE, as Secretarias de Educação que aderiram ao programa de formação continuada, a proposta de atendimento em parceria com a família, o professor regente, o professor de AEE e uma equipe multidisciplinar.

Concluindo, pode-se dizer que essa política de inclusão dos "excluídos do interior” (BOURDIEU, 2001) é uma tentativa de romper com práticas racionalistas de classificação e desclassificação que a sociedade adota para justificar certas práticas educativas baseadas em concepçóes de normalidade "criadas ou inventadas" a partir da visão cartesiana do homem, 
conforme ideia foucauldiana, que diferencia e isola sujeitos que não são "providos de razão". Ou mesmo romper a lógica de diferenciação já narrada por George Orwell (1945, p. 53), escritor inglês, em sua obra Revolução dos Bichos, quando diz: "Todos os animais são iguais, mas alguns são mais iguais que outros.” É contrário a essa premissa que o AEE insere-se nas políticas públicas de educação inclusiva como uma possibilidade para reescrever a história dos "desprovidos de racionalidade" e da escola inclusiva.

\section{Referências}

ANDRADE, A. L. C. Atendimento Educacional Especializado: uma proposta inclusiva para alunos com surdez. 2011. Trabalho de Conclusão de Curso (Especialização em formação continuada de professores para o Atendimento Educacional Especializado - AEE área de educação especial) - Faculdade de Educação, Universidade Federal do Ceará, Fortaleza, 2011.

BOURDIEU, P.; CHAMPAGNE, P. Os excluídos do interior. In: BOURDIEU, P. Escritos de educação. 3. ed. Petrópolis: Vozes, 2001.

BRASIL. Constituição da República Federativa do Brasil. Brasília: Imprensa Oficial, 1988.

- Ministério da Educação. Lei de Diretrizes e Bases da Educação Nacional. LDB 9.394, de 20 de dezembro de 1996.

. Decreto n. 6.517/2008. Disponível em: <http://peei.mec.gov.br/arquivos/Resol_4_2009_CNE_CEB.pdf>. Acesso em: 21 nov. 2011. MEC/ SEESP, 2009.

CARVALHO, S. F. de A. Atendimento Educacional Especializado para educandos com deficiência física: um estudo de caso no Ensino Fundamental. 2011. Trabalho de Conclusão de Curso (Especialização em formação continuada de professores para o Atendimento Educacional Especializado - AEE área de educação especial) - Faculdade de Educação, Universidade Federal do Ceará, Fortaleza, 2011.

CONVENÇÃO da GUATEMALA para a Eliminação de todas as formas de Discriminação contra as Pessoas Portadoras de Deficiência. 1999. 
Disponível em: <http://www.ampid.org.br/Docs_PD/Convencoes_ONU_ PD.php\#guatemala>. Acesso em: 25 nov. 2011.

CONVENÇÃO relativa à Luta Contra a Discriminação no Campo do Ensino. Disponível em: <http://www.gddc.pt/direitos-humanos/textos-internacionais-dh/tidhuniversais/pd-conv-cdiscriminacao-ensino.html>. Acesso em: 22 nov. 2011.

CONVENÇÃO Interamericana para a Eliminação de Todas as Formas de Discriminação Contra as Pessoas de Deficiência. Disponível em: <http:// www.turismoadaptado.com.br/pdf/legislacao_internacional/convencao_interamericana_de_deficientes.pdf>. Acesso em: 22 nov. 2011.

DANTAS, E. B. O processo de inclusão escolar: estudo de caso de uma aluna com deficiência intelectual e Síndrome de Angelman. 2011. Trabalho de Conclusão de Curso (Especialização em formação continuada de professores para o Atendimento Educacional Especializado - AEE área de educação especial) - Faculdade de Educação, Universidade Federal do Ceará, Fortaleza, 2011.

FÁVERO, E. A. G.; PANTOJA, L. de M. P.; MANTOAN, M. T. E. Atendimento Educacional Especializado: aspectos legais e orientação pedagógica. Brasília: SEESP/SEED/MEC, 2007.

FOUCAULT, M. História da loucura. 9. ed. São Paulo: Perspectiva, 2010. . A verdade e as formas jurídicas. Rio de Janeiro: NAU, 1999.

GONÇALVES, V. de S. Atendimento Educacional Especializado: um estudo de caso de crianças com deficiência física na educação infantil. 2011. Trabalho de Conclusão de Curso (Especialização em formação continuada de professores para o Atendimento Educacional Especializado - AEE área de educação especial) - Faculdade de Educação, Universidade Federal do Ceará, Fortaleza, 2011.

LEITE, M. T. L. Atendimento Educacional Especializado para criança com autismo: um estudo de caso. 2011. Trabalho de Conclusão de Curso (Especialização em formação continuada de professores para o Atendimento Educacional Especializado - AEE área de educação especial) - Faculdade de Educação, Universidade Federal do Ceará, Fortaleza, 2011. 
MANTOAN, M. T. E. Atendimento Educacional Especializado. Fortaleza: UFC, 2010.

ORWELL, G. A revolução dos bichos. Disponível em: <http://inlivros.net/ download/236/a-revolucao-dos-bichos-george-orwell.html>. Acesso em: 21 jul. 2012.

SANTOS, A. A. G. O AEE e o aluno com Transtorno Global do Desenvolvimento: Autismo. 2011. Trabalho de Conclusão de Curso (Especialização em formação continuada de professores para o Atendimento Educacional Especializado - AEE área de educação especial) - Faculdade de Educação, Universidade Federal do Ceará, Fortaleza, 2011.

SANTOS, S. C. G. Atendimento Educacional Especializado: estudo de caso de uma criança autista. 2011. Trabalho de Conclusão de Curso (Especialização em formação continuada de professores para o Atendimento Educacional Especializado - AEE área de educação especial) - Faculdade de Educação, Universidade Federal do Ceará, Fortaleza, 2011.

SILVA, M. R. S. Deficiência Intelectual: estudo de um caso real. 2011. Trabalho de Conclusão de Curso (Especialização em formação continuada de professores para o Atendimento Educacional Especializado - AEE área de educação especial) - Faculdade de Educação, Universidade Federal do Ceará, Fortaleza, 2011.

VERDE, A. L.; POULIN, J. R.; FIGUEIREDO, R. V. de. In: RAPOLI, E. A. et al. A Educação Especial na Perspectiva da Inclusão Escolar: a escola comum inclusiva. v. 1. Brasília: Ministério da Educação, Secretaria de Educação Especial; [Fortaleza]: Universidade Federal do Ceará, 2010.

Recebido em: 29 nov. 2011.

Aceito em: 20 jan. 2011. 